\title{
Correspondence
}

\section{Continuing the debate - the role of the medical ethicist}

SIR,

Thank you for your explanation of the official policy of the $\mathcal{Y} . M . E$. in the last (June) issue. We appreciate that the fournal is intended to be an open forum for the multidisciplinary study of the moral issues raised by the practice of medicine and that its aim is to examine the underlying moral beliefs and theories that lead to differing conclusions. We did not suggest that you should be 'hortatory', or indulge in 'medical moralising', or impose a 'rigid moral dogmatism'. But if the study of moral issues does not lead to a practical outcome which helps the individual doctor - what is the point of all the discussion?

What appears to be happening so often today is that, on the positive side, we empirically and impartially collect all possible data on what is being done and what can be done in a particular medical situation. On the negative side all value judgments from philosophy and religion, and the wisdom of past ages, are excluded. We then sit down before the unadorned facts and try to come to the appropriate moral conclusion.

But, surely, medical ethics can never have 'an autonomy of its own'? We must bring something to the facts which few have assembled. What we bring is our understanding of human nature and what is right and wrong in human conduct. The obvious example is abortion. A knowledge of the facts of pregnancy and the techniques for its termination will not enable any doctor to decide what to do in a particular case. On the other hand, if the doctor regards human life as sacrosanct he will be most reluctant, or may refuse, to comply with the patients' wishes. But, if he regards the fetus as a potential life or not yet human he may see nothing wrong in removing it. His concept of life shapes his decision, but he will probably bring other secondary attitudes to bear.

The fournal plays a very valuable part in stimulating thought but it declines to offer any moral guidelines. As you express it, 'If a sound clinical judgment depends upon knowledge, a sound moral judgment will only result where there is both knowledge and a freedom of choice'. But how is it possible to make a moral judgment out of mere knowledge - however extensive that knowledge may be? The logic of what you say is that in urgent and sometimes complicated situations the doctor, be he general practitioner or consultant physician, can - if armed with neutral knowledge and freedom of choice - determine the moral issue ? But can he ? Ought he?

If such an approach to ethics is allowed to stand, does it not mean that we shall all be swept onward by the prevailing popular notions of the day with regard to the rights and wrongs of human conduct. The clamour of contradictory voices is all around us today and he who shouts loudest is most easily heard. Doctors also are strongly influenced by what they hear and read. How can medical ethics ever be 'neutral' without in the end running the risk of betraying humanity itself ?

May we end by quoting from a recent publication edited by Hunt and Arras - Ethical Issues in Modern Medicine? '... in adopting a particular ethical stance, we commit ourselves to a certain way of being and a certain way of regarding ourselves and our relationship with others. As Plato said, "For no light matter is at stake; the question concerns the very manner in which human life is to be lived".'

C GORDON SCORER DOUGLAS JOHNSON Hillingdon

SIR,

The statement of the aims and nature of the Fournal of Medical Ethics by Lord Amulree and
Prebendary E. F. Shotter was most helpful. It is timely that a journal exists to stimulate the introduction of an element of reflection into an apprenticeship which has been often notably unreflective. The absence of reflection contrasts with activities and activism in all areas of the health care field which become increasingly frenetic, particularly in the United States. Thankfully, there are still opportunities and outlets to share sober, non-hortatory reflection.

However, in reading the issue in which the letter of Lord Amulree and Prebendary Shotter appears, I find myself being exhorted to engage in some cause in practically every article. For example, 'There seem to be sensible grounds for reappraisa of attitudes to incest...' 1 Ever more strongly advocated is 'the responsibility and duty of all of us to secure proper ethical conditions for the persual of medicine and science free from the constraints of ulterior motives which governments may from time to time seek to impose,' 8 and I suppose a particularly tendentious exortation is ' We should seek to ensure that both heterosexual and homosexual households have very open attitudes to sex in their homes.' 3 These recommendations are neither unexpected nor necessarily inappropriate as medical ethicists typically are in an activist and some would say an evangelistic phase. Proponents of a wide spectrum of political, social and religious thought have discovered this arena for what is proving a valuable dialogue. I am, therefore, left puzzled why the views of your contributors Scorer and Johnson were severely handled. The authors are accused of appearing 'to want the appearance of moralising in the name of religion' and 'to have confused proselytising with the study of medical ethics.' I must confess that having read their letter carefully on several occasions, I fail to sense these aims. They simply ask whether any particular consensus guides the 
Editorial Board of the fournal and, indeed, specifically eschew dogmatic utterances. Admittedly they clearly approve the Kantian imperative and their letter implies that they are probably rule deontologists. However, rule deontology has been and remains a perfectly respectable ethical position. I trust that what appears to be an over sensitive response to the views expressed by Scorer and Johnson does not reflect preference on the part of the fournal, positively or negatively, for any group of ethical theories.

\section{References}

${ }^{1}$ Nobel and Mason. fournal of Medical Ethics 4: 68, 1978.

${ }^{2}$ Merskey. Ibid. pp. 74-77.

3Pietroni. Ibid. p. 94.

ALASTAIR M. CONNELL Cincinnati, Ohio 45267

\section{Mental disease}

SIR,

Whilst agreeing substantially with Dr. Flew's drift (Mental disease, fournal of Medical Ethics, 1978, 4, 89-90) I find he has oversimplified his argument to the point of rendering it naive.

He suggests that mental disease must necessarily involve some sort of incapacity and/or discomfort in the persons thus afflicted. He maintains that this much is essential to the notion of disease. Subsequently he discusses the inadequacies of concepts of mental illness which he considers do not measure up to this essential; the central plank of his thesis is that physical diseases do.

Let us examine this plank. There are a number of physical diseases which do not involve discomfort or incapacity, e.g. benign pulmonary sarcoidosis, often detected on routine chest X-ray, essential hypertension in its early stages, and others. Are these not to be considered diseases ? Moving into the realms of personal choice and will, does he consider that cigarette smoking (as a known precursor of organic damage) does not come within the province of the physician because it does not present as a complaining patient ?

His argument that mental illness should not be considered as a type of deviant behaviour is attractive. However, in the most severely incapacitated paranoid schizophrenic, about whom little typological doubt exists, it is other people who decide that the person is incapacitated and then usually on the grounds of a description of the syndrome in behavioural terms. It is inhumane to consider that this condition be dealt with by any agency other than the medical profession yet the form of definition of disorder is qualitatively the same as, say, the definition of a football hooligan. It is not possible therefore to distinguish, using Dr. Flew's criteria, between mental illness and misfits or rebels.

This does not mean that this cannot and should not be done. It certainly seems inevitable that predominant societal attitudes will adjust the fine tuning of this process.

In America, and Dr Flew uses one American author heavily, the consumerism of medical practice encourages the medicalisation of many problems of living. Few American psychiatrists would turn away a patient, I suspect, however trivial his complaint, and indeed psychoanalytic theory (very prominent in American practice) justifies involvement in any persons life if that person wishes it. It is also true to say that the same theory or at least the majority of its practitioners would not consider it helpful to incarcerate and treat against their will such a person-indeed it cannot be done since the therapy depends upon a will determined commitment.
In this country consumer medicine is not predominant and the medical model, in a sophisticated form, is not: disowned or despised by the majority of psychiatrists. It is recognised for what it is, a pragmatic modus operandi with major deficiencies, but one which has not yet been superseded.

Dr Flew should read British authors on the problems of definitiono and diagnosis in psychiatry for a fulp exposition of this point. ${ }^{1}$ To return to societal attitudes, he rightly under? lines the dangers of the definitiona $L$ problem. He produces the Sovief Union as an example of a society which misuses the mental illness concept. This is of course correct but an inevitable consequence of the combination of two elements. One is $\vec{r}$ the totalitarian régime which attempts to define desirable social behaviours? and attitudes centrally, and then to impose those attitudes on the people, and the other is the actual continuunfs of disturbed behaviour in individuals. along which the mental illnes cut-off point is arbitrarily set.

In this country a variety of socia震 forces inter-relate to set this cut point which will from time to the become solidified in a Mental Heath Act this being an uncomfort醉ie compromise.

It is not possible by Dr Flew' criteria to produce a workable humane system for distinguishing mentally ill persons. To conclude as he does that the patient's com? plaining alone should be the arbiter, is to deny many suffering individual their right to assistance and, in many. cases, recovery.

\section{References}

${ }^{1}$ Kendall, R. E., (1975) The Role of Diagnosis in Psychiatry, Blackwe Scientific.

IAN CLARK Dundeg 